other than that which they are following at the moment. There is less leakage of students entering technical colleges from the junior technical schools than of students of any other type.

Dr. Richardson considers that the raising of the school age would assist the work of the technical colleges; but if education is to be effective, it must be compulsory until the age of mental maturity-at least until eighteen. The idea of the local college, which is a community of students whose main purpose in attending is educational, and not social, but for whom the authorities must provide facilities for social and physical development in the fullest sense, is gaining ground. Such colleges would necessarily continue to have a vocational and industrial bias, endeavouring to develop skill as well as to impart technical knowledge and training in administration both in the industrial and the civic sphere.

Mr. F. Pick, whose paper drew the warm approval of Mr. H. G. Wells, criticized education for failing to give to the new subjects of an industrial civilization the breadth and quality which is given to the older subjects bred in the classic ages. He argued for a new type of university of the eye and hand as distinct from that of the voice and the pen. It should be possible to illuminate the accumulated knowledge of trade and industry with a wisdom and understanding which would make it a suitable medium for a liberal education. The trained and broadened mind should be applied to the building up out of the mass of knowledge which they embody, human sciences to rank with ethics, politics, economics and sociology.

Prof. Winifred Cullis followed with a final paper in which she dealt with some questions confronting the universities in the changing world. With regard to the aims of university education, there is a great consensus of opinion as expressed both by staff and by students, and the stress is laid on training for living rather than for a livelihood. She referred to a number of particular problems raised in recent reports, such as the question whether a specialist training for particular careers is the best for developing leaders of informed public opinion, for men and women who are to be politicians, administrators, journalists or teachers. Again, there is the question whether post-graduate teaching should be concentrated in particular universities, in which connexion
Prof. Cullis referred to the backward position of postgraduate education in medicine in Great Britain compared with that in other countries. The extension of the system of individual tutorship to all universities, and increased facilities for short-term ex. changes of staff between different universities both in Great Britain and abroad, and the provision of increasing numbers of residential halls are all matters requiring consideration.

Prof. Cullis laid particular stress on the importance of greater attention to the question of the health of students, and strongly supported the demand for physical education and health services at the universities. She is in favour of compulsory medical examinations at regular intervals, pointing out that it is often the students who can least afford medical advice who most need it and that such examination could often prevent serious illness developing later. She outlined a number of health insurance schemes, both optional and compulsory, which have been developed for students in Great Britain or abroad, and finally stressed the importance of including training for the responsibilities of citizenship.

Lord Stamp, who opened the discussion, was decidedly more critical than Mr. H. G. Wells of Mr. Pick's paper. He pointed out that we cannot say what changes in education are desirable until we have decided what is the right direction for such changes to take; what is the optimum speed at which they should be made; how they can be made with the least waste; and what should be the correct agencies for bringing them about. Some account must now be taken of the changes in the rate of growth of the population and of its possible physical obsolescence, and Lord Stamp referred particularly to the importance of considering training which would give the right outlook and background to those occupying the intermediate executive positions, since they have so much influence on the selection from the younger men and women of those who in later life will occupy the positions of highest responsibility. He strongly supported the idea of refresher classes and post-graduate courses for those already occupying business or professional posts. Sir Richard Livingstone criticized the teaching of history and philosophy at an age too early for adequate appreciation, and expressed his regret that adult education had not been included in the discussion.

\title{
New Science Buildings at Shrewsbury School
}

\begin{abstract}
$\mathrm{O}^{\mathrm{N}}$ September 24, Sir William Bragg, president of the Royal Society, opened the new science building at Shrewsbury School. Charles Darwin was at the School from 1818 until 1825, and the building, hitherto used for science teaching, erected in 1903, was named after him. It has been considerably re-modelled and improved for chemistry teaching under the present building programme. The new building was dedicated "in thankful commemoration of the life and work of Charles Darwin".

The new science building comprises two floors, the ground floor being devoted to physics, and the first floor to biology. The latter floor is some two thirds the area of the ground floor and is masked on three faces by roof slopes, it being the desire that this new building should conform to the general style of
\end{abstract}

adjacent buildings, which are mostly of one story. The construction is of brick, with hollow tile fireresisting floors, and tiled roofs with asphalt flats between. All rooms are fully plastered, and floors generally are of teak blocks. Heating is by lowpressure hot water radiators.

The ground floor (physies) has two large elementary laboratories, each for 26 students, with a common preparation - store room, an advaneed laboratory for 16 students, two lecture rooms to seat 26 each, a large store room and a photographic dark room. Both elementary laboratories are alike in fitments; long fixed double-sided table type benches, having gas and electric services, occupy the middle of the room. Fnclosed balance cases in groups are disposed around the walls, and two large sinks are 
conveniently situated in each room. The advanced laboratory is fitted with a 'service shelf' 15 in. wide around three sides of the room (having gas, water and electric services thereon), which when used in conjunction with the four strong loose tables gives considerable flexibility.

The elementary laboratories and lecture rooms contain fully equipped demonstration benches, and a certain amount of local storage is provided in all rooms. All rooms have dark blinds. Free wall space is fitted with battens for fixing and hanging apparatus, and the laboratories have beams suspended from the ceiling for the usual physical experiments. Built-in slate galvanometer shelves are provided in convenient positions, those in the lecture rooms having measuring leads and 12-volt light leads connected to the demonstration benches for demonstration work with mirror galvanometer and ground glass scale.

Large yellow glass 'boards' (in place of the more usual blackboards) have been used throughout. Experimental electrical services consist of switch plugs to all working spaces, which in the elementary laboratories can be used on the 230 volts A.C. supply or alternatively on 12 volts A.c., one pair of leads only being used (designed to avoid varying voltage drops). Voltage reduction is by 'step-down' transformer and change-over switch under the supervision of the master. Direct current supplies for the advanced laboratory and all demonstration benches at 24 volts is provided from a battery of cells and an oxide cathode rectifier, interchange of voltage being carried out by plug and socket distribution board arrangement. All the D.c. equipment is located on one wall of the advanced laboratory and is available for instructional purposes.

The first floor (biology) consists of two very large well-lighted laboratories, a common preparation room, store room, greenhouse, and a small private research room for the masters' use. Except for incubator accommodation in one room and aquaria in the other, both large laboratories are identical in fitments, one portion of each room being laid out with flat-topped tables and seats for 24 students (for theoretical work), with fully equipped demonstration bench, projection screen, and 'yellow board', the other portion fitted with low benches (for 26 students) for microscope and dissecting work. These latter benches have gas points and microscope light points fitted, and are designed to accommodate microscopes and their lamps when not in use. There are two large wash-up sinks and drainers in each laboratory, with provision for draining and storing dissecting boards, and around all walls one continuous shelf allows of the display of natural history specimens and specimens 'in embryo'. North-east top lights are provided over that part of each laboratory devoted to practical work, and dark blinds are provided throughout. Storage and preparation rooms provide accommodation graded to suit all sizes from small stain bottle racks to large diagram charts.

The old building has been considerably re-modelled internally to provide the necessary accommodation exclusively for chemistry, comprising two large elementary laboratories (one for fifth-form work), two large lecture rooms, an advanced (specialist) laboratory for 14, two balance rooms, the usual store and preparation rooms and a small science library. Existing fittings have been modernized, new chemistry working benches provided where necessary, and new ranges of fume cupboards in the fifth-form laboratory and advanced laboratory have been installed, ventilated by a centrifugal fan and acidresisting ducting. New roof lights have been added to improve the natural lighting of the rooms.

The architects for the work were Messrs. Munby and Smith, of 9 Old Square, Lincoln's Inn, London.

\section{Effect of Inbreeding of Physiologic Races of Rust}

$\mathrm{T}$

HE recognition of the + and - strains in rust fungi and the way in which the bi-nucleate aecial condition must be preceded by mycelial fusion of + and - strains or the introduction of pycniospore-containing nectar of the opposite strain, has led to the possibility of the study of inbred physiologic races. Johnson and Newton (Can. $J$. Res., 16 ; 1938) have made a study of the effects produced in Puccinia graminis Tritici Erikss. and Henn. Cultures have been started from a single urediospore and these have been followed through their cycle, selfing being brought about by mixing pycniospore-containing nectar of pustules of the isolated race.

It is found in several of the isolated races, when selfing has been repeated for several generations, that new features are liable to appear. Thus races which originally had the normal red uredial colour have produced types with greyish-brown, orange or white uredia-features which are of extremely rare occurrence in Nature. The proportions in which these abnormalities of uredial colour appear suggest a genetic relation in which greyish-brown and orange are dominant to white, and the normal red to the other three.

Also in such inbred races types have appeared with decreased vigour of uredia as evidenced by a tendency towards or failure of the uredial pustules to break through the host epidermis; other types have shown a weakening of pathogenicity, as compared by inoculation of named varieties of wheat, and still others have failed to produce aecia and instead formed urediospores or teliospores on the barberry.

The authors point out that mutations have been reported several times for the rusts, and the evidence from the present work suggests that certain physiologic races are in a mutable condition. Owing to the multiplicity of physiologic races and the heterothallic nature of the rusts, in Nature the mutants will seldom occur in the homozygous condition. When inbreeding is maintained for several generations, it is probable that homozygous recessive types are segregated (or possibly additional mutations occur during the selfing stages on barberry).

In the group of the rusts, short-cycle forms are of relatively common occurrence and may tend towards the production of autoecious species. In this connexion it is of interest to find in Puccinia graminis a mutant in which the aecial stage is eliminated, though the urediospores produced on the barberry are only capable of infecting wheat seedlings, so that the physiologic race is still heteroecious. 